\title{
Escola em tempo integral no campo: conflitos de ideias
}

Rosa Maria da Silva ${ }^{1}$, Antonio Sales ${ }^{2}$

${ }^{1}$ Universidade Estadual de Mato Grosso do Sul - UEMS. Programa de Pós-Graduação em Educação. Avenida Dom Antonio Barbosa, MS-080, 4.155. Campo Grande - MS. Brasil. paiolzinhorosa@ hotmail.com. ${ }^{2}$ Universidade Estadual de Mato Grosso do Sul - UEMS e Universidade Anhanguera - UNIDERP.

RESUMO. Este trabalho faz uma análise sobre discursos e conceitos referentes à Educação de Tempo Integral, ao mesmo tempo em que aponta algumas ideias da população do campo de Corumbá-MS a respeito do tema. A política em questão não é recente, porém, é objeto de discussões na atualidade. O Governo Federal pretende implantar o modelo integral em $50 \%$ das escolas brasileiras até 2024. A pesquisa revela que grande parte da comunidade do campo é desfavorável a esta política e que apesar das boas intenções, a implantação da escola de tempo integral evidencia a permanência de certo descaso para com a população do campo, pois, sua concepção além de basear-se no modelo das cidades educadoras, em nenhum momento menciona o campo, é como se este espaço não existisse, ou fosse insignificante, levando em conta o grande valor dado à cidade. A metodologia utilizada fundamentou-se em leituras bibliográficas, entrevistas semiestruturadas, conversas informais com os pais, ou, responsáveis por alunos que estudam em uma escola Rural no município Sul-mato-grossense de Corumbá.

Palavras-chave: Educação no Campo, Escola de Tempo Integral, Concepção. 


\title{
Full - time school in rural community: ideas in conflict
}

\begin{abstract}
This study has analyzed concepts and speeches about fulltime education, at the same time, it points out some ideas from the farmers population of Corumbá-MS about this subject. The policy in question is not recent, but it is the target of discussions today. The Federal Government goal is to implement the full-time model school, at least, in $50 \%$ of Brazilian schools by 2024 . The research reveals that a large part of the rural community is unfavorable to this policy, regardless of its good intention, to establish the full-time rural school demonstrates that the Government neglects rural communities, because its conception is not only based on educating cities but also it did not even mention the rural area and its population, it is like this area may just as well not exist. Or it was insignificant. Rural community does not even know what a fulltime school is. Considering the great value given to the city. The methodology used here was based on bibliographical readings, semi-structured interviews, friendly talks with some parents or tutors of students who study at a rural school in Corumbá-Mato Grosso do Sul.
\end{abstract}

Keywords: Education in Rural Communities, Full-Time Schools, Conception. 


\section{Escuela de tiempo completo en el campo: conflictos de ideas}

RESUMEN. Este trabajo hace un análisis sobre discursos y conceptos referentes a la Educación de Tiempo Integral, al mismo tiempo que apunta algunas ideas de la población del campo de Corumbá-MS, al respecto del tema. La política en cuestión no es reciente, sin embargo, es objeto de discusiones en la actualidad. El Gobierno Federal pretende implantar el modelo integral en el 50\% de las escuelas brasileñas hasta 2024. La investigación revela que gran parte de la comunidad del campo es desfavorable a esta política y que, a pesar de las buenas intenciones, la implantación de la escuela a tiempo completo evidencia la permanencia de cierta negligencia con la población del campo, pues, su concepción aparte de basarse en el modelo de ciudades educadoras, en ningún momento menciona el campo, es como si este espacio no existiera, o fuera insignificante, teniendo en cuenta el gran valor dado a la población del campo. La metodología utilizada se basó en lecturas bibliográficas, entrevistas semiestructuradas, conversaciones informales con los padres o responsables de alumnos que estudian en una escuela rural en el municipio Corumbá-Mato Grosso do Sul.

Palabras clave: Educación en el Campo, Escuela de Tiempo Integral, Concepción. 


\section{Introdução}

Considerando que a concepção Educação Integral se baseia nos discursos das cidades educadoras, uma proposta que conta com os arredores das escolas, citando a exemplo, museus, bibliotecas, cinemas, teatros, igrejas como fontes de conhecimentos e espaços colaboradores da aprendizagem integral, o presente trabalho faz uma reflexão sobre a implantação deste modelo no campo.

A Lei de Diretrizes e Bases da Educação Nacional 9394/96 (LDBEN) e as Diretrizes Operacionais para Educação Básica no campo garantem nesse espaço uma educação que considere as especificidades e culturas dos seus povos. Porém, os livros e discursos dos defensores da Educação Integral, cito a exemplo, a professora Jaqueline Moll, uma das percussoras do programa no Brasil, sequer mencionam sobre o currículo ou atividades para educação integral nas escolas do campo. Outra questão a ser considerada diz respeito ao que pensa a população do campo sobre escola em tempo integral, uma vez que em seus discursos a política pretende se dar com a participação direta da comunidade, inclusive nas escolhas das atividades.

Diante da possibilidade de se implantar a educação integral no campo nos mesmos moldes defendidos para a cidade, é possível indagar se com o passar do tempo e após tantas lutas por uma educação básica no campo, esse campo ficou realmente visível, ou, o que existe são políticas compensatórias?
Desde a sua colonização, a educação do Brasil costuma seguir os moldes educacionais europeus, ou, latino americanos, numa forma de herança cultural urbanizada. No entanto, as condições de funcionamento das escolas neste país sempre foram precárias, principalmente no campo. Nunca existiam escolas suficientes, as estruturas físicas eram inadequadas, havia escassez de recursos materiais e humanos, os educadores das escolas do campo não tinham formação ideal e recebiam remuneração inferior aos professores da cidade.

Os trabalhadores rurais em sua grande maioria nem frequentavam escolas, seus direitos não eram garantidos. Segundo Nascimento (2009), as primeiras constituições sequer mencionavam a Educação do campo:

O Brasil mesmo considerado um país eminentemente agrário, sequer mencionava acerca da educação rural em seus textos constitucionais de 1824 e 1891, o que evidencia dois problemas de governança pública a saber: o descaso por parte dos dirigentes com a educação destinada aos camponeses e resquícios de uma cultura política fortemente alicerçada numa economia agrária com base no latifúndio e no trabalho escravo. (Nascimento, 2009, p. 160).

Esse descaso permaneceu por muito tempo, inclusive, em outras constituições, nas próprias pesquisas o assunto educação do campo só surge nas últimas décadas. Segundo Arroyo, Caldart \& Molina (2009, p. 8), o silenciamento, esquecimento e até o desinteresse sobre o rural nas pesquisas sociais e educacionais é um dado histórico que se tornava preocupante.

\section{Alguns aspectos da educação do campo}

\begin{tabular}{|l|l|l|l|l|l|l|l|}
\hline Rev. Bras. Educ. Camp. & Tocantinópolis & v. 2 & n. 2 & p. $773-792$ & jul./dez. & 2017 & ISSN: 2525-4863 \\
\hline
\end{tabular}


É nos últimos 20 anos que os trabalhadores em meio à luta pela terra começam a se preocupar com a educação da sua gente, assim, reivindicações por um olhar mais específico acerca da educação do campo se intensificam, encontros e seminários são realizados em vários estados e municípios do país no sentido de se pensar em uma educação voltada à realidade dessa gente. Essas mobilizações começam a ganhar apoio:

As universidades, centros de pesquisa, se voltam sensibilizados para produzir referenciais teóricos e capazes de dar nova dinâmica do campo brasileiro, milhares de educadores se reúnem, debatem, estudam e refazem concepções e práticas educativas em escolas camponesas, em escolas famílias agrícolas, em escolas de reassentamentos do Movimento dos Atingidos pelas Barragens, em escolas de Assentamentos e Acampamentos dos Sem Terra, ou em escolas de comunidades indígenas e quilombolas (Arroyo, Caldart \& Molina, 2009, p. 9).

Então, em 1990, com esses movimentos organizados de forma mais articulada essa realidade começa a mudar, surgem às reivindicações pela criação de políticas públicas para a população do campo. Em se tratando da educação, o objetivo maior era a criação de propostas pedagógicas que respeitassem essa realidade, especialmente as formas de produzir, lidar com a terra e a história dos povos do campo. Esses pensamentos têm origem na pedagogia de Freire, que sempre defendeu uma educação que considerasse a realidade do sujeito. Ele fala que:
Quando o homem compreende a sua realidade, pode levantar hipótese sobre o desafio dessa realidade e procurar soluções. Assim pode transformá-la e o seu trabalho pode criar um mundo próprio, seu Eu e as suas circunstâncias. (Freire, 1979, p. 30).

Molina e Sá também falam da importância de práticas educativas que orientem seus sujeitos e suas práticas, vejam:

A educação do Campo, nos processos educativos escolares, busca cultivar um conjunto de princípios que devem orientar as práticas educativas que promovem com a perspectiva de oportunizar a ligação da formação escolar à formação para uma postura na vida, na comunidade $\quad-\quad o$ desenvolvimento do território rural, compreendido este como espaço de vida dos sujeitos camponeses. (Molina \& Sá, 2012, p. 329).

Em meio a esses espaços públicos de debates são elaboradas algumas concepções sobre educação do campo e em seguida implementam-se reformas educacionais que desencadearam documentos, dentre eles: a nova Lei de Diretrizes e Bases da Educação Nacional 9394/96 (LDBEN), que em seu artigo 28 estabelece as seguintes normas:

$\mathrm{Na}$ oferta da educação básica para a população rural, os sistemas de ensino proverão as adaptações necessárias à sua adequação, às peculiaridades da vida rural e de cada região, especialmente: Iconteúdos curriculares e metodologia apropriada às reais necessidades e interesses dos alunos da zona rural; Iorganização escolar própria, incluindo a adequação do calendário escolar às fases do ciclo agrícola e às condições climáticas; II- adequação à natureza do trabalho na zona rural. (Brasil, 1996).

Em 2003 são implantadas, por ocasião do grito da terra Brasil/2003, as Diretrizes 
Operacionais para a Educação Básica nas Escolas do Campo, que são reafirmadas na II Conferencia de Educação do Campo em agosto de 2004, as quais foram implantadas pelo governo federal porque vem de encontro a um processo inovador de construção de políticas públicas. O Ministério da Educação "assume o compromisso, organizado com os povos do campo" de forma compartilhada com os diversos sujeitos governamentais e não governamentais comprometidos com a afirmação de um modelo de desenvolvimento sustentável-ecológico, equânime e inclusivo também aos povos do campo (Diretrizes Operacionais para Educação do Campo Resolução CNE/CEB n. ${ }^{\circ} 03$ de abril de 2002).

Diante da premissa de uma educação que envolva o respeito à identidade e à realidade do sujeito, muitos autores se posicionam nessa defesa, veja a fala de Rosseto:

Pensar a escola do campo é pensar num projeto político-pedagógico que se vincula ao projeto de ser humano e um projeto de sociedade, pois na maioria das vezes a escola que está localizada no campo trabalha conteúdos fragmentados, ideias soltas, fora da realidade, sem relação entre si e muito menos com a vida concreta; são muitos os estudos e atividades sem sentido, fora de uma totalidade mais ampla. Pois entendemos que educar é também ajudar a construir e a fortalecer identidades; é formar sujeitos de história. E isso tem a ver com valores, modo de vida, memória, cultura. Isto também é uma das funções da escola do campo (Rosseto, 2005, p. 27).

É interessante observar que, mesmo diante de todas essas conquistas, a educação no campo ainda enfrenta descaso, um exemplo é o
Plano Nacional de Educação, que não menciona nem traz dados sobre o campo no tópico que trata da valorização do magistério e formação de professores. Nessa mesma ótica de falta de menção ao campo, surge a Educação de Tempo Integral.

\section{Educação integral: conceitos/discursos}

A Discussão sobre o tema Educação de Tempo Integral tem sido algo frequente nos bastidores das televisões, em programas e vídeos do YouTube, principalmente por parte de dirigentes responsáveis por políticas públicas no Brasil. Autores como Cavaliere (2009, 2010), Azevedo (1932), Paro et al. (1988a; 1988b), Moll (2009), Gadotti (2004), entre outros, têm se manifestado sobre o assunto. Apesar de ser um discurso que surge no Brasil entre os anos de 1920 e 1930, com os Movimentos dos Pioneiros da Educação ou Movimento Escola Nova, na prática oferecer educação integral nas escolas públicas brasileiras no intuito de universalização do modelo é algo novo e a concepção a respeito do tema é carregada de divergências, inclusive entre os autores.

Compreensão que predomina sobre a educação integral é de que esta deveria proporcionar o desenvolvimento integral do educando durante toda a sua vida. Tal desenvolvimento se daria em decorrência de todas as experiências educativas que se possam ser oferecidas, englobando aspectos intelectuais, físicos, artísticos, éticos e emancipatórios. Defende-se também a educação integral como meio para difundir a 
mentalidade e as práticas democráticas, seria então uma educação vinculada a um projeto político e ideológico.

Nesse sentido, Cavaliere acrescenta:

No Brasil, a compreensão da maneira pela qual a concepção de educação integral se desenvolve passa obrigatoriamente pelo estudo do pensamento educacional das décadas de 20 e 30 do século XX. A educação integral, significando uma educação escolar ampliada em suas tarefas sociais e culturais esteve presente nas diferentes correntes políticas que se delinearam naquele período. As correntes autoritárias e elitistas a encapavam com o sentido de ampliação e dos processos de distribuição criteriosa dos indivíduos nos seguimentos hierarquizados da sociedade (Cavaliere, 2010, p. 209).

Um documento resultante do Manifesto dos Pioneiros e da Escola Nova, escrito em 1932 por 26 intelectuais, entre eles, Anísio Teixeira, apresentou uma visão de educação que englobava as diferentes dimensões humanas, cuja responsabilidade do estado seria organizar e tornar efetiva a escola num modelo que deveria romper com seu isolamento, interagindo com o meio e com outras instituições sociais. Segundo Azevedo, o manifesto destacava que:

Do direito de cada indivíduo a sua educação integral, decorre logicamente para o estado, que o reconhece e o proclama, o dever de considerar a educação, na variedade de seus graus e manifestações, como uma função social eminentemente pública, que ele é chamado a realizar, com a compreensão de todas as instituições sociais ... Assentado o princípio do direito de cada indivíduo à sua educação integral, cabe evidentemente ao estado a organização dos meios de tornar efetivo (Azevedo, 1932, p. 5).
Fica evidente, portanto, que o Manifesto dos Pioneiros reivindicava não apenas a responsabilidade pública do estado para com a escola, mas também, um engajamento da sociedade através da participação de instituições sociais nesse processo. Essa visão assistencialista continua presente até hoje ao implantar a educação em tempo integral, inclusive, criticada por Paro et al. (1998a), que nesse sentido diz:

O Estado na tentativa de atender as reivindicações e pressões da população por mais instruções, responde com propostas de escolas em tempo integral, na qual o propósito principal não é a divulgação do saber sistematizado, mas a solução de problemas sociais localizados além dos limites da escola e que têm natureza não propriamente pedagógica (Paro et al. 1988a, p. 14).

Na visão desse autor a escola precisa dar conta, primeiramente, do conhecimento científico, algo que para ele não acontece ainda no Brasil. Sua crítica faz sentido quando se refere à educação voltada à solução de problemas sociais. Para nos convencermos disso basta observarmos a forma como vem sendo implantada essa educação em tempo integral em nosso país, muitos questionamentos partem das próprias comunidades, no campo, além da falta de estrutura nos prédios, os pais questionam a real necessidade desse tempo maior do aluno na escola uma vez que uma das justificativas para se implantar esse modelo está evidentemente ligada a problemas sociais que ocorrem na cidade, segundo a Secretaria de Educação, Continuada, Alfabetização e Diversidade SECAD (2009): 
O PNE associa a progressiva ampliação do tempo escolar às "crianças das camadas sociais mais necessitadas", às "crianças de idades menores, das famílias de renda mais baixa, quando os pais trabalham fora de casa". Nesse sentido, o Plano valoriza a educação em tempo integral especialmente nos seus aspectos pertinentes à assistência social (Brasil, 2009, p. 22).

Apesar das famílias no campo, em sua maioria, serem de baixa renda, elas se diferenciam em várias situações daquelas residentes na cidade. Os discursos referentes a pais que trabalham fora, a questão da vulnerabilidade da criança, o argumento de ficar exposta à violência, criminalidade, drogas e explorações das ruas, são discursos que não se encaixam na definição da realidade camponesa, pois, ao contrário da cidade, no campo a maioria das mães não trabalha fora, dedicam seu tempo justamente a cuidar da família.

De forma geral não existe um consenso ou uma concepção única a respeito da educação em tempo integral. De um lado discute-se como seu princípio fundamental, a formação ampla e emancipatória do cidadão. De outro, discursos e ações se apresentam como forma de resolver problemas sociais, na tentativa de melhorar a qualidade de vida do educando e da sua família.

Além desses embates, há outras falhas presentes em sua elaboração, uma delas é a negação da existência dos povos e escolas do campo em seus conceitos. Fica absolutamente visível pela leitura e interpretação de vários autores que esse modelo de escola é especialmente criado para as cidades e bairros.
No entanto, não se pode afirmar que o campo foi excluído na prática dessa política, ao contrário, em Corumbá, Mato Grosso do Sul, por exemplo, mais de $50 \%$ das escolas do campo já funcionam em tempo integral. Bastam algumas leituras para perceber que essas escolas se desenvolvem segundo o modelo imaginado, desenhado e elaborado para a cidade, um modelo que busca inspiração no conceito de "cidades educadoras" visto no discurso de Gadotti, por exemplo, que diz:

... na cidade que educa todos os seus
habitantes usufruem da mesmas
oportunidades de formação,
desenvolvimento pessoal e de
entendimento que ela oferece. O
"manifesto das cidades educadoras",
aprovado em Barcelona em 1990, afirma
que a satisfação das necessidades das
crianças e dos jovens, no âmbito das
competências do município, pressupõe
uma oferta de espaços, equipamentos e
serviços adequados ao desenvolvimento
social, moral e cultural... (Gadotti, 2004,
p. 02).

Mais adiante o autor continua:

\begin{abstract}
A cidade oferece aos pais uma formação que lhes permita ajudar os filhos a crescer e utilizar a cidade num espírito de respeito mútuo. Todos os habitantes da cidade têm o direito de refletir e participar de programas educativos e culturais, e a dispor de instrumentos necessários que lhes permitam descobrir um projeto educativo, na estrutura da gestão da cidade, nos valores que esta fomenta, na qualidade de vida que oferece, nas festas que organiza, nas campanhas que prepara, no interesse que manifesta por eles e na forma de escutar (Gadotti, 2004, p. 02).
\end{abstract}

É importante indagar qual o lugar do campo nos discursos da educação em tempo integral. Afinal como se daria, por exemplo, o acesso dos alunos localizados fora da cidade, a 
espaços como museus, teatro, bibliotecas, cinemas, especialmente porque nos arredores de suas escolas inexistem tais parceiros. Será que nos planos do governo existem recursos para que isso ocorra?

\section{A escola do campo no cenário da política Educação Integral}

As Políticas Públicas de Educação escolar contemporâneas no Brasil pressupõem que a educação é um direito de todos os indivíduos. Nesse sentido, a Educação em tempo integral é direito de todos, garantido hoje na Nova Lei de Diretrizes e Bases Nacional 93.94/96, que em seu artigo 34 ressalta a jornada escolar mínima de quatro horas diárias e uma ampliação do tempo e permanência do aluno na escola, sendo explicitado no inciso $2^{\circ}$ que "o ensino fundamental será ministrado progressivamente em tempo integral, a critério dos sistemas de ensino" (Brasil, 1996), ficando submetido aos sistemas de ensino sua organização.

Em 2007 os Ministérios da Educação, da Cultura, do Desenvolvimento Social e Combate à Fome e do Esporte, lançaram o Programa Mais Educação, o qual teria objetivo de orientar recursos para "Fomentar a educação integral das crianças, adolescentes e jovens por meio de atividades sócio educativas no contra turno escolar" (Brasil, 2009, p. 24). O que é previsto também no decreto $\mathrm{n}^{\circ} 7.083$ de 2010, veja:

Art. $1^{\circ} \mathrm{O}$ Programa Mais Educação tem por finalidade contribuir para a melhoria da aprendizagem por meio da ampliação do tempo de permanência de crianças, adolescentes e jovens matriculados em escola pública, mediante oferta de educação básica em tempo integral.

$\S 1^{\circ}$ Para os fins deste decreto, considerase educação básica em tempo integral a jornada escolar com duração igual ou superior a sete horas diárias, durante todo o período letivo, compreendendo o tempo total em que o aluno permanece na escola ou em atividades escolares em outros espaços.

$\$ 2^{\circ}$ A jornada escolar diária será ampliada com o desenvolvimento das atividades de acompanhamento pedagógico, experimentação e investigação científica, cultura e artes, esporte e lazer, cultura digital, educação econômica, comunicação e uso de mídias, meio ambiente, direitos humanos, práticas de prevenção aos agravos à saúde, entre outras atividades. $\S 3^{\circ}$ As atividades poderão ser desenvolvidas dentro do espaço escolar, de acordo com a disponibilidade da escola, ou fora dela, sob orientação pedagógica da escola, mediante o uso dos equipamentos públicos e do estabelecimento de parcerias com órgãos públicos ou instituições locais (Brasil, 2010).

Paro (2013, online) diz que a escola não está dando conta nem do conhecimento científico. Para o autor, "não é função da escola essa assistência social, visível nas intenções da Escola de Tempo Integral" uma crítica que faz sentido, pois, um dos envolvidos em tal política é o Ministério do Desenvolvimento Social e Combate à Fome. Em consonância com os pensamentos de Paro e com as colocações dos entrevistados em relação à questão estrutural-administrativa, é possível afirmar que o governo também não dá conta de manter financeiramente nem o que já existe hoje.

A crítica aqui apresentada se deve também à experiência vivenciada com a implantação do Programa Mais Educação 
numa escola rural de Corumbá-MS, na qual era gestora. O recurso recebido pela escola em 2012, para atender o Programa, em sua maior parte destinava-se aos monitores. $\mathrm{O}$ restante ficou composto de uma porcentagem mínima para o material pedagógico e outra menor ainda para o permanente. No entanto, a orientação do órgão competente era de que todos os alunos deveriam frequentar a escola em seus contraturnos, seguindo então assim, uma jornada ampliada.

Contudo, muitos problemas surgiram, por exemplo: os ônibus disponíveis para atender uma média de 175 por turnos passariam a atender 350 . Se todos viessem em seus contraturnos, não haveria espaço na escola, ou, na comunidade. Como se isso não bastasse, falta um coordenador para organizar, acompanhar e orientar as atividades, pois, o Programa, conforme o decreto de $\mathrm{n}^{\mathrm{o}} 7.083$, de 27 de janeiro de 2010, prevê o acompanhamento de um coordenador (Brasil, 2010).

As políticas públicas são pensadas para a cidade e transportadas para o campo sem uma avaliação mais profunda sobre as especificidades existentes em cada realidade, inclusive, pelas leituras até aqui realizadas desconheço qualquer publicação atual que fale sobre educação integral nas escolas do campo no sentido de garantir a integração da escola com seu entorno, com a comunidade e com a família. Afinal, que espaços e instituições existentes nessas realidades podem colaborar como insiste a proposta desse modelo integral, na aprendizagem do aluno?
Nos conceitos implicados no modelo de educação em tempo integral, apresentados por Jaqueline Moll, ex-diretora de Currículos e Educação Integral da Secretaria de Educação Básica do Ministério da Educação, está presente a ideia de um currículo que considere saberes cotidianos do mundo e da vida:

\footnotetext{
- a valorização dos saberes popular como saberes legítimos a serem trabalhados/incluídos no "currículo escolar", implicada em uma profunda mudança cultural, uma vez que revisita toda a tradição cartesiana que reduz os saberes e modos de expressão populares a irracionalismos, crendices e tradições infundadas;

- a revisão dos currículos escolares para a valorização tanto dos saberes clássico (patrimônio da humanidade nos vários campos) quanto dos saberes cotidianos do mundo da vida (Moll, 2009, p. 15).
}

Diante disso é preciso questionar: que saberes são propostos nos currículos das escolas de tempo integral no campo? Será que os saberes destes povos são considerados ou recebem os saberes urbanos como parâmetro, como se sua cultura, seus conhecimentos não tivessem nenhum valor? Será que alguma atividade do contraturno dessas escolas do campo levam em consideração seus sujeitos, sua realidade, o contexto de suas redondezas?

Ao ler os artigos publicados no livro: Trajetórias Formativas em Educação Integral no estado de Mato Grosso do Sul, é possível identificar o quanto os pensamentos e discursos sobre educação integral estão voltados para a escola da cidade. Observe abaixo a fala dos autores de um dos artigos presentes no livro, ao tratarem dos espaços institucionais que formam uma comunidade de 
aprendizagem de uma escola integral, após citarem uma fala de Pacheco, dizem:

Desta forma, o conceito de cidade educadora em interface com a educação integral suscita a proposição de que a cidade e seu entorno é um local rico de vivencias e experiências, proporcionando uma infinidade de possibilidades de vivência e cidadania. E, segundo Moll (2004), a cidade forma uma rede de espaço formais e informais que a transformam em um território educativo, um espaço de trocas e de promoção da cidadania e solidariedade (Moraes \& Aniceto, 2016, p. 39).

Nas considerações finais esses autores falam novamente citando a cidade dizendo que:

Também é preciso promover articulação da escola com a cidade, permitindo que o processo de ensino e aprendizagem ocorram nos diferentes espaços da comunidade, bairro, promovendo a valorização da cultura local e a participação familiar (Moraes \& Aniceto, 2016, p. 41-42).

Num outro artigo do mesmo livro, mais adiante, Piatti (2016) ao falar do compromisso e desafio da escola integral e integrada faz a seguinte observação em relação à criança: "Não the basta oferecer diversas atividades apenas para preencher o tempo, elas precisam estar acopladas aos conteúdos. É preciso articular escola e cidade como um dos territórios educadores". (Piatti, 2016, p. 81). Mas à frente ela repete: "na escola integral a educação não acontece e nem deve acontecer apenas nas salas de aulas e no interior da escola, é preciso sair desse espaço e acontecer em outros ambientes (cidade, bairros, ruas e comunidade)". (Piatti, 2016, p. 82).
Ainda no livro citado (Trajetórias Formativas em Educação Integral no Estado de Mato Grosso do Sul), Eliane Guaraldo fala em seu artigo sobre um movimento que difundiu o conceito de cidade educadora ocorrido em 1990, em Barcelona, que resultou 4 anos depois na Associação Internacional das Cidades Educadoras - (AICE), que integra mais de 400 cidades de 35 países, incluído o Brasil. Este aparece com 35 cidades tendo Belo Horizonte como cidade coordenadora. Segundo a autora, o conceito formulado envolve a percepção de que as cidades educadoras estimulam e oferecem vias de realização a capacidade educadora que todos da cidade têm, podendo nesse sentido promover um crescimento melhor e/ou desenvolver as potencialidades e projetos das pessoas e dos grupos humanos. Após esse entendimento a autora acrescenta:

A cidade é necessariamente educadora e todos os seus elementos têm uma potencialidade educadora implícita e permanente. Mas a forma como se coloca esse potencial educador a serviço da conexão entre grupos e da integração com outras formas de educar é que a torna, de fato, cidade educadora (Guaraldo, 2016, p. 143).

Gadotti ao falar das cidades educadoras diz: "Na cidade que educa todos os seus habitantes usufruem das mesmas oportunidades de formação, desenvolvimento pessoal e de entretenimento que ela oferece" (Gadotti, 2004, p. 02).

Alguns municípios estão implantando a Educação em Tempo Integral no campo antes mesmo de se implantar na cidade. Corumbá é 
um exemplo, já transformou 03 das 05 escolas rurais em escolas de tempo integral, enquanto das 23 escolas urbanas apenas 02 funcionam neste modelo.

Diante de um cenário de pouco discurso sobre esse modelo integral no campo cabem aqui algumas perguntas: o que os pais entendem sobre educação em tempo integral? Será que os povos do campo partilham dos pensamentos dos povos da cidade? Esses questionamentos surgiram num momento em que se percebeu, entre alguns pais de uma determinada comunidade rural de Corumbá, anseios e rejeição a ideia do filho ficar o dia inteiro na escola.

\section{O que pensam os pais que vivem no campo a respeito da escola de tempo integral?}

Como acadêmica de curso de Mestrado Profissional em Educação da Universidade Estadual de Mato Grosso do Sul - UEMS elaborei um projeto de pesquisa no intuito de aprofundar meus estudos a respeito da implantação da escola de tempo integral no campo, uma pesquisa que evidentemente será realizada em escolas já contempladas nesse modelo. No entanto, a ideia deste artigo surgiu após ser informada de que mais uma escola rural se tornaria integral em 2017, um trabalho que pode vir a somar a minha futura dissertação de mestrado, possibilitando inclusive algumas comparações do antes e depois da implantação desse modelo integral no campo.

Foi realizada, então, uma pesquisa de campo cujos métodos utilizados foram: conversas informais e questionários semiestruturados sobre os pensamentos dos pais a respeito da escola ou educação de tempo integral no campo. Sessenta e cinco (65) pais foram entrevistados, um número que representa mais ou menos $80 \%$ de pais dos estudantes do ensino fundamental da unidade escolar referida.

A princípio percebeu-se que os pais olhavam a entrevistadora de uma forma indagadora, pareciam tentar descobrir através do olhar de quem lhes abordava o que esperava que falassem. Talvez o fato da entrevistadora ser educadora os levasse a pensar que a sua opinião fosse favorável ao modelo de escola em tempo integral. Afinal, trabalhando o dia inteiro, certamente teria um salário melhor, um deles chegou a expressar esse pensamento. Geralmente ela olhava para os entrevistados e dizia: por favor, sinta-se à vontade para dar a sua opinião. Isso os deixava mais à vontade, alguns olhavam mais seguros e diziam: então eu vou falar! Assim, a pesquisa se deu de maneira bastante tranquila. Buscava sempre deixá-los à vontade para responder os questionários. Alguns falavam ou respondiam as perguntas com um pouco de insegurança, outros defendiam com muita firmeza seus pensamentos. Analisaremos então o que a maioria disse não à Escola em Tempo Integral.

Questão 01 - Dos 65 pais entrevistados 44 (cerca de 68\%) se mostraram desfavoráveis à Escola de Tempo integral e apresentaram os seguintes motivos (Quadro 1). 
Quadro I: Motivos apresentados para serem desfavoráveis.

\begin{tabular}{|l|c|}
\hline \multicolumn{1}{|c|}{ Motivos } & $\mathrm{N}^{\circ}$ De Pais \\
\hline $\begin{array}{l}\text { A questão da presença do } \\
\text { filho em casa, próximo dos } \\
\text { pais por questão de cuidado, } \\
\text { afeto, zelo...; }\end{array}$ & 15 \\
\hline $\begin{array}{l}\text { Acham que a escola não tem } \\
\text { estrutura. }\end{array}$ & 12 \\
\hline $\begin{array}{l}\text { Necessitam do apoio dos } \\
\text { filhos em casa. }\end{array}$ & 08 \\
\hline $\begin{array}{l}\text { Acham que vai atrapalhar o } \\
\text { Ensino Médio e E.J.A. }\end{array}$ & 05 \\
\hline A criança cansará muito. & 03 \\
\hline Acredita não ser necessário. & 01 \\
\hline \multicolumn{1}{|c|}{ Total } & 44 \\
\hline
\end{tabular}

Fonte: Elaborado pelos autores.

Questão 2 - Você tem filhos no Ensino Fundamental da Escola Municipal Rural? Em que série?

- Todos responderam que sim. Dentre eles duas respostas são das próprias alunas que responderam por elas, uma por que o pai estava na roça e a outra por já estar casada (as duas do fundamental). Os pais tinham filhos nas diversas séries do Ensino Fundamental.

Questão 3 - Você poderia explicar o que é Educação Integral ou Escola de tempo Integral?

Quadro 2: Respostas dos pais à questão de número 3.

\begin{tabular}{|l|c|}
\hline \multicolumn{1}{|c|}{ Respostas } & $\mathrm{N}^{\circ}$ De Pais \\
\hline $\begin{array}{l}\text { Explicaram à sua maneira } \\
\text { simples. }\end{array}$ & 02 \\
\hline Não souberam explicar & 24 \\
\hline $\begin{array}{l}\text { Responderam que é um tempo } \\
\text { maior na escola }\end{array}$ & 36 \\
\hline $\begin{array}{l}\text { Consideram um reforço ou } \\
\text { complementação em outro } \\
\text { turno }\end{array}$ & 03 \\
\hline
\end{tabular}

\begin{tabular}{|l|c|}
\hline Total & 65 \\
\hline
\end{tabular}

Fonte: Elaborado pelos autores.

Questão 4 - A meta do governo é tornar 50\% das escolas brasileiras em Escolas de Tempo integral até 2024. Há duas escolas rurais vizinhas que já funcionam em tempo integral e a intenção do órgão competente é transformar também a escola do seu filho neste modelo de escola. Você concorda? (Quadro 3).

Quadro 3: Respostas à questão de número 4:

\begin{tabular}{|c|c|}
\hline RESPOSTAS & $\mathrm{N}^{\circ}$ DE PAIS \\
\hline São a favor & 14 \\
\hline São contra & 44 \\
\hline Em dúvida & 07 \\
\hline Total & 65 \\
\hline
\end{tabular}

Fonte: Elaborado pelos autores.

Questão 5 - Considera que esse tempo maior na escola pode ser melhor para seu filho, ou, no sítio ele poderia aprender mais?

Quadro 4: Respostas à questão de número 5.

\begin{tabular}{|l|c|}
\hline RESPOSTAS & $\mathrm{N}^{\circ}$ De Pais \\
\hline $\begin{array}{l}\text { Acreditam que ajuda na } \\
\text { aprendizagem }\end{array}$ & 31 \\
\hline $\begin{array}{l}\text { Responderam que tanto as escolas } \\
\text { como a família podem passar } \\
\text { aprendizagem, porém, cada uma de } \\
\text { uma forma. }\end{array}$ & 12 \\
\hline \begin{tabular}{l} 
Defenderam a educação em casa \\
\hline $\begin{array}{l}\text { Acreditam que essa aprendizagem } \\
\text { depende de vários fatores entre eles } \\
\text { citaram professor, condições } \\
\text { favoráveis, interesse do aluno. }\end{array}$
\end{tabular} \\
\hline $\begin{array}{l}\text { Afirmam que essas atividades } \\
\text { podem ser desenvolvidas em } \\
\text { horário parcial. }\end{array}$ & 09 \\
\hline \begin{tabular}{l} 
Total \\
\hline
\end{tabular} & 65 \\
\hline
\end{tabular}

Fonte: Elaborado pelos autores. 
Questão 6 - Dentre os temas a serem trabalhados cita-se a questão da sustentabilidade, você, considera importante que a escola do campo trabalhe com esse tema, envolvendo atividades voltadas ao campo, como hortaliças, agricultura, pecuária, história do aluno e do local, reforma agrária, por que?

- Todos favoráveis.

Os participantes são moradores das seguintes regiões (Quadro 05)

- Assentamento TI-03

- Assentamento TII S - 33

- Assentamento TII N - 02

- Assentamento PU-10

- Região CF4 - 14

- Região J5 - 02

- Região SP6 - 01

\section{Discussão e análise dos dados}

Observa-se que a maiorias dos entrevistados entende que Educação Integral é a oferta de educação num tempo maior para a criança.

De certa forma alguns resultados da pesquisa surpreendem quem está acostumado a ouvir os discursos de que no campo os filhos ajudam os pais uma vez que as famílias sobrevivem da agricultura familiar de subsistência. Sabendo que o trabalho é coletivo e todos colaboram, inclusive os filhos, é de se supor que as respostas contraditórias relativas à educação em tempo integral se dariam nesse sentido. No entanto, foi possível observar não só pelos questionários, mas também nas conversas informais, especialmente com as mães, que o principal motivo é o cuidado, o zelo pelo filho e não a falta que eles fazem no trabalho. Muitas mães sentem-se inseguras por entenderem que a escola não cuidará tão bem quanto elas; outras, por sua vez, fazem questão desse tempo maior para cuidar do seu filho. É o afastamento do filho que as incomoda.

A seguir algumas falas referentes à questão 03, que pergunta aos campesinos se são a favor da escola de tempo integral:

Não quero. Se meu filho ficar o dia inteiro na escola é por que vai ser obrigado, isto é, sem a minha vontade. Ficar mais de sete horas lá?! Eu vou ser obrigada a ficar longe dele. Que hora que vou ter com ele? Já vai chegar cansado, com um pouquinho [mais de tempo] vai jantar e dormir. Vou ser privada [como mãe]da minha parte de educar. Eu gosto quando ele chega da escola e vou fazer tarefas com ele. Eu tenho o que ensinar pra ele também, eu não sou contra o pai que quer, mais cada pai tem que ter a sua responsabilidade com o filho. Muitos querem, por que é [está] cansado, entregar o filho no órgão público, descuidar da educação moral (...). Você vê que tem criança que vai para a escola com a roupa do outro dia, sem nem lavar o rosto. Tem muito dever que é da família. Ele já estudou em integral quando eu morei no Pantanal. Chegava cansado, não tem [tinha] fôlego, a minha participação era isolada, não trazia nem tarefa, por que essa hora da tarefa até a gente aprende com eles. $\mathrm{O}$ ensino integral num traz tarefa é uma privação minha com ele. (Mãe 01).

Não, por que meus filhos não terão tempo para ficar com a família e pelo tempo [que ficam] fora de casa. Não tem necessidade disso, pois o tempo normal é suficiente para a aprendizagem que eles necessitam, pois eu mesma aprendi assim. (Mãe 02).

Não concordo. Meu filho é pequeno, vai começar a estudar agora esse ano. Oito horas é muito tempo para ele em relação às atividades. Não acredito que ajudem tanto, pois, o aprendizado dos meus filhos, pra mim está ótimo em 4 horas de estudo. (Mãe 03). 
Não. Por que para mim a escola ensina e a família educa. $\mathrm{Na}$ escola com tempo integral a criança fica muito ausente, [e] o contato com a família diminui, fica o dia inteiro na escola. A criança precisa do contato com os pais, [não pode] fica[r] longe. [O filho]chega cansado, vai dormir e a afetividade com a família, em casa [?] Ele pode aprender muita coisa [conosco]também, nossa cultura também. (Mãe 04).

Foi surpreendente a concepção dessa última mãe a respeito da Educação de Tempo Integral, ela resume: "para mim a educação integral é a ausência do filho muito tempo fora de casa" (em resposta à pergunta de número 02).

Esse zelo, essa defesa da presença do filho em casa, como uma necessidade de protegê-lo e dar carinho, apareceu com muita frequência nas falas das mães que têm filhos pequenos, principalmente daqueles que estão iniciando os estudos. $\mathrm{Na}$ zona rural é comum as crianças entrarem na escola direto no Pré-II, porque as mães preferem que fiquem em sua companhia.

O Art. 205 da Constituição nos diz: “A Educação, direito de todos e dever do Estado e da família, será promovida e incentivada com a colaboração da sociedade e sua qualificação para o trabalho". (Brasil, 1988). Este artigo proclama o direito da família na educação dos seus filhos. Nas conversas com as mães surgiram algumas indagações delas do tipo: o que é educar?

Às vezes vai à escola e chega em casa cheio de gíria, palavrões, maus costumes, com malcriação, que aprendem com colegas. [Aprendem] coisas que em casa ensinamos que é errado, então, independente de escola a família também educa. Eu mesma não quero que o meu [filho]vá por que aqui eu sei o que está fazendo, dou educação também, e lá, será que vão olhar mesmo? (Mãe 25).

Outra mãe afirmou: "Não, prefiro que a tarde eles fiquem comigo, que eu tô vendo né o que tá fazendo". (Mãe 05).

A questão da companhia também apareceu entre as preocupações. Vejamos a fala de uma avó:

$\mathrm{Eu}$ não. Às vezes a gente precisa da criança né, eu mesmo só tenho ele, né?! $\mathrm{E}$ [se] fica o dia inteiro na escola (...). Eu crio, ele é meu neto, eu nessa idade! Já cheia de doença, problema de pressão, é ruim ficar tanto tempo sozinha. Ele já tem 13 anos é também uma companhia, né?. (Avó 01).

A questão do apoio aos filhos em casa não ficou de fora. Algumas falas a respeito:

Numa parte eu sou "mei" a favor né!? Mais eles tão crescendo e "nóis" ficando "véi” (...). A gente precisa "di" apoio, "as geração" de jovem no campo tá acabando, quem vai ser nosso sucessor aqui, eu "tem" esse sítio "bunito", tem uma chácara grande lá na cidade, vejo aí gente vendendo o sítio, aqui já tem gente com seis sete lote, eu acho que os "fi" tem que ter o contato com eles(sítio) pra intender, aprender a lidar, agente num sabe o que vão escolher. Eu também num vejo muita alternativa viu, o povo aumenta poucos produzem e muitos comem, olha o preço do feijão! É por que poucos produz[em]. Eu vejo esses esportes aí, o prefeito "investi" dinheiro, você vai lá e "cum uns dia as quadra" e praça já tá tudo destruído! (Pai 07)

Sou contra por que meu filho no sítio ajuda bastante, meu filho, por exemplo, ajuda na horta já tem seu pedaço de roça e precisa cuidar. No horário integral ele não terá tempo para cuidar dos canteiros que ele fez para ele aqui em casa. (Mãe 01)

A mãe continua sua fala informalmente dizendo: 
A lei fala de negócio de não puder ajudar mais, meu filho estudou na Fundação Bradesco e lá eles trabalhavam. Eu acho que tem que ajudar, é por isso que tem muita criança malandra por aí na cidade. Um monte de jovem roubando celular e tudo mais, por que o pai perdeu o direito de educar o filho, [de] ensinar a trabalhar. (Mãe 01).

Não, porque é cansativo né! E os mais "velho ajuda" em casa, é pra olhar um irmão mais novo, é pra dar água [para] um animal, ajudar fazer a comida quando "os pai tão" na roça. Fala[m] que essa atividade ajuda, a minha nesse ano se destacou em dança na escola, dança que é uma beleza! Mas, aprender a ler mesmo que é bom não aprendeu foi nada, até "reprovô". (Mãe 02).

A fala dessa mãe apresenta uma concepção bastante comum entre as pessoas que vivem do campo. É que, para eles, dança, música, teatro, capoeira, entre outras atividades culturais, não têm valor. É tão presente essa concepção que alguns afirmavam que mandavam os filhos para o reforço (Acompanhamento Pedagógico) do Programa Mais Educação, mas, para outras oficinas não, inclusive por conta de religião.

A resposta do pai $n^{\circ} 07$ vem ao encontro dessa matéria da Federação dos Trabalhadores em Agricultura do Rio Grande do Sul FETAG/RS 2005 que fala sobre a sucessão no sítio:

... o aprendizado e a consequente opção e afirmação do jovem e da jovem pela agricultura se dá, em grande medida, graças à convivência e pela interação ocupacional desde a mais tenra idade. A opção pela profissão de agricultor/a familiar não ocorre após os 16 ou 18 anos (período em que legalmente alguém pode trabalhar), mas vai sendo construída, definida e consolidada ao longo do período de convivência e aprendizado com a família ... (FETAG/RS, 2005, p.5).

A discussão sobre a educação do campo está presente em estudos de vários autores, entre eles, Caldart (2003, 2004), defensora de uma educação no campo que respeite e considere a realidade dessa gente que lutou e luta pelo direito a terra e pela educação dos seus filhos no próprio campo, bem como seu desenvolvimento. Para Caldart (2003), a escola tem papel fundamental na formação de um indivíduo crítico e capaz de atuar na busca da emancipação do seu meio e dos seus companheiros:

Não há escolas do campo num campo sem perspectivas, com o povo sem horizontes e buscando sair dele. Por outro lado, também não há como implementar um projeto popular de desenvolvimento do campo sem um projeto de educação, e sem expandir radicalmente a escolarização para todos os povos do campo. E a escola pode ser um agente muito importante de formação da consciência das pessoas para a própria necessidade de sua mobilização e organização para lutar por um projeto deste tipo (Caldart, 2003, p. 64).

A fala do pai $\mathrm{n}^{\circ} 07$ apresenta ainda a questão da evasão do jovem e da própria família do campo, a falta de estrutura provavelmente é um dos maiores motivos. No entanto, para Caldart um ensino escolar eminentemente urbano reforça o conceito de que no campo não é lugar digno de se viver, assim, a escola acaba colaborando para muitos jovens evadirem do campo.

Essa discussão não se faz presente nos conceitos da educação integral, especialmente porque não se prevê em seus estatutos a 
educação no campo. Recordemos a análise feita anteriormente sobre o fato deste modelo, ter como base o conceito de "Cidades educadoras".

Diante disso, não seria necessário um momento para se elaborar um projeto de oficinas mais específicas para as escolas do campo? Um projeto que desperte o interesse da comunidade em participar juntamente a escola? Afinal, os defensores da escola em tempo integral afirmam que "O mapeamento de espaços, tempos e oportunidades é tarefa que deve ser feita com as famílias, os vizinhos, enfim, toda a comunidade" (Brasil, 2009, p. 16).

Pensando que até o momento os espaços apresentados na proposta são aqueles dos arredores da escola como: cinemas, praças, museus, teatros, bibliotecas.... Uma questão relevante é: como tem sido a participação das comunidades do campo nesse mapeamento?

Voltando às entrevistas, uma das respostas que se destacou na justificativa dos pais que não querem a escola de tempo integral foi à questão da estrutura, vejam:

Não, porque ou a escola não tem estrutura adequada para os alunos. (Mãe 07)

Tenho uma filha especial já acompanho ela o meio período, fica difícil ter que ficar o dia inteiro na escola. (Mãe 08)

Não, por que não tem recurso para a escola ser integral. (MÃE 09)

Não, a escola não tem estrutura para manter os alunos num horário só! (Mãe 10)

Não, do jeito que tá a escola não vejo como isso acontecer, não tem estrutura, banheiro em péssimas condições, a sala de computação nem funciona mais, e tem gente pra cuidar lá? (Mãe 11).

O estudo é muito bom né, mas, vejo que é sacrificante, devido o tempo que acriança passa no ônibus, a escola não tem estrutura, é preciso planejar antes com a comunidade. (Pai 5).

A falta de estrutura para se implantar a escola de tempo integral, ou educação integral, já vem sendo questionada por alguns autores, veja:

$\mathrm{Na}$ impossibilidade de ampliar o atendimento em horário integral - até hoje considerado um privilégio pelo investimento que envolve - muitas redes municipais vêm oferecendo atividades extraclasses que representam algumas horas a mais na escola. Em algumas redes, permite-se que alunos do ensino fundamental frequentem os dois turnos escolares, numa forma precária e improvisada de oferta de horário integral. (Castro \& Faria, 2002, p. 85).

É possível observar que, apesar de a maioria desejar ou necessitar da presença do seu filho em casa por mais tempo, conseguem entender que a escola é o lugar do conhecimento científico, porém, acredita-se que pela falta de estrutura que existe, não iria fazer muita diferença esse novo tempo integral.

Outra grande preocupação dos pais merece ser considerada aqui. A Escola em estudo é a única na região que atende os alunos no ensino médio. Apesar de ser uma escola municipal, há um convênio entre estado e município que envolve cedência de espaço e uso do transporte escolar. Duas salas no período matutino e três no período noturno são ocupadas por alunos do estado. Para os pais, ao se transformar em escola de tempo integral, 
esta escola não cederá mais as salas no período matutino ao estado, uma vez que o espaço não seria suficiente para atender todos os alunos das duas redes. Alguns pais não querem seus filhos estudando à noite por uma questão de cuidado.

Veja algumas dessas falas:

Não concordo, porque o ensino médio pode ser prejudicado, a noite já só é duas horas, ai vão fazer igual em Albuquerque três vezes por semana, diminui o nosso tempo, o que adianta bota uns para estudar mais e tirar dos outros, o melhor é deixar do jeito que está. (Mãe 23).

$\mathrm{Eu}$ até concordaria, mas pretendo fazer o ensino médio. (Mãe 33).

Eu não concordo, inclusive se fô assim do dia inteiro, vou ter que me mudar daqui eu não quero minhas filhas estudando a noite, ficar de ajuntamento, num acho bom não. (Mãe 14).

A mãe número 12 cita Albuquerque, uma região vizinha. Ela quis dizer que se a escola da sua comunidade se tornar integral logo o ensino médio funcionará três vezes por semana, pois foi o que aconteceu na Escola Rural de Albuquerque, onde os alunos do estado também ocupam salas do município. Levando em conta que os alunos do ensino médio irão todos para o período noturno e que à noite, entram no horário das 19h00min e saem às $21 \mathrm{~h} 30 \mathrm{~min}$, serão muito prejudicados.

Nem mesmo os alunos que responderam por si mesmos concordaram com esse modelo de escola. Mi (pseudônimo) tem 15 anos e, como a maioria das meninas do campo, já está morando junto com um menino. Considera-se casada. Para ela: "a escola não tem recurso para ser integral e não acredita que essas atividades vão ajudar a desenvolver melhor o aprendizado".

Outra aluna de 14 anos respondeu que não tinha interesse em ficar o dia inteiro na escola.

Atualmente, os pais estão preocupados, porém, não sabem ao certo se a escola vai se tornar integral em 2017ou não, apesar de alguns preparativos para tal ato em 2016.

\section{Considerações finais}

Algumas preocupações da comunidade evidenciam a falta de políticas públicas condizentes com as necessidades do campo.

Os dirigentes públicos na tentativa de resolverem os problemas educacionais criam suas metas com datas marcadas para se cumprirem em todos os territórios sem consultar ou verificar as reais necessidades das diferentes comunidades. A implantação de tais políticas, buscando garantir mais educação, normalmente resultam em mau atendimento das demandas. Um exemplo claro é o programa mais Educação, que oferece o monitor, mas não oferece espaço adequado. Outro caso é o Ensino Médio, que na zona rural de Corumbá não funciona como se prevê a Lei. $\mathrm{O}$ aluno tem direito de 800 horas aulas anuais, porém, estuda, em média, de $02 \mathrm{~h} 15 \mathrm{~min}$ por dia. O prejuízo é grande. Voltando a Paro (2013), quando diz que "a escola não dá conta nem do que se propõe", é perceptível a inserção de políticas pragmáticas que se demonstram de caráter assistencialista, denotando também o cumprimento de 
promessas eleitorais moldadas por pensamentos ideológicos e demagógicos.

Após vários anos de debates, encontros e seminários promovidos pelos movimentos sociais na luta pela garantia de uma educação no campo que respeite a realidade camponesa, uma conquista já garantida no art. 28 LDB 9.394/96, a educação do campo vive hoje um momento de estagnação. Poderíamos ir mais além e afirmar certo há certo grau de retrocesso nesse setor. Uma questão preocupante é que aqueles que discutiam essa educação parecem adormecidos, pois, permitem, sem questionar, que o campo seja contemplado com políticas públicas idealizadas para a cidade, como é o caso desse novo modelo de escola de tempo integral baseado num discurso totalmente urbano.

Faz-se necessário e urgente estudos que analisem de forma crítica essa implantação, pois é preciso questionar se a tal política pública está realmente preocupada com a formação integral que abrange, em sentido mais amplo a todos os educandos, possibilitando-lhes o verdadeiro exercício da cidadania. Ou se essa implantação é apenas um cumprimento de promessas políticas feitas aos brasileiros. Pode-se afirmar que a elaboração da política de escola ou educação integral desde a sua concepção é fragmentada e excludente, uma vez que não considera as diferentes realidades, bem como a diversidade cultural.

Considerando a afirmação de Caldart (2005) “... de que o povo tem direito a ser educado no lugar onde vive...", entendemos que o povo tem direito a uma educação pensada desde o seu lugar e com sua participação, vinculada a sua cultura e suas necessidades humanas e sociais. Assim, é preciso considerar que além de cidades educadoras existe o campo, um espaço rico que também pode ser educador e parceiro da escola. Sobre essa perspectiva, faz-se necessário no mínimo uma revisão nas atuais concepções de educação integral, de forma que se estude e considere todos os espaços, numa discussão que valorize as diversidades como parte da educação integral.

\section{Referências}

Arroyo, M. G., Caldart, R. S., \& Molina, M. C. (Orgs.) (2009). Por uma educação do campo. Petrópolis, RJ: Vozes.

Azevedo, F. F. et al. (1932). Manifesto dos Pioneiros da Educação Nova: a reconstrução educacional no Brasil - ao povo e ao governo. Rio de Janeiro: [s.n]. Recuperado de: www.pead.faced.ufrgs.br/site/publico/eixos/or ganização/gestão/modulo3/querosaber mais.pdf/5p

Brasil. (1961). Lei n.4.024 de 20 de dezembro de 1961. Fixa as diretrizes e bases da educação nacional. Lex: Legislação Federal.

Brasil. (1988). Constituição da República Federativa do Brasil. Brasília-DF: Diário Oficial.

Brasil. (1996). Lei de Diretrizes e Bases da Educação Nacional - LDB N 9.394/96. De 20 de dezembro de 1996. Brasília.

Brasil. (2008). Ministério da Educação (MEC), Secretaria de Educação Continuada, Alfabetização, Diversidade (Secad). Programa Mais Educação, passo a passo. Brasília. 
Brasil. (2009). Educação Integral: texto referência para o debate nacional. - Brasília: Mec, Secad.

Brasil. (2010). Decreto $n^{o} 7.083$ em 27 de janeiro de 2010. Dispõe sobre o Programa Mais Educação.

Caldart, R. S. (2003). A escola do campo em movimento. Currículo sem Fronteiras, 3(1), 60-81.

Caldart, R. S. (2005). Elementos para a construção do projeto político pedagógico da Educação do Campo. Cadernos Temáticos: educação do campo. Curitiba: SEED/PR.

Castro, A. R. V., \& Faria, L. C. M. (2002). CIEP: o resgate da utopia. In Coelho, L. M. C.; Cavaliere, A. M. A. V. (Orgs.). Educação brasileira e(m) tempo integral. (pp. 133-146). Petrópolis, RJ: Vozes.

Cavaliere, A. M. (2009). Escolas de tempo integral versus alunos em tempo integral. Em Aberto, 22(80), 51-63.

Cavaliere, A. M. (2010). Anísio Teixeira e a educação integral. Paidéia, 20(46), 249-259.

CENPEC. (2015). Educação e Participação. Guia Políticas de Educação Integral. s.d. Recuperado de: https://guia.educacaoeparticipacao.org.br/prop osta-curricular//

FETAG-RS, Sucessão Rural. (2005). Recuperado de: http://www.fetagrs.org.br/site/index.php?idp= $\underline{\mathrm{NTI}=\& \mathrm{ids}=\mathrm{NTc}}$

Freire, P. (1979). Educação e mudança. Rio de Janeiro: Paz e Terra.

Gadotti, M. (2004). A escola na cidade que educa. São Paulo-SP: Cortez/ IPF.

Guaraldo, E. (2016). Cidades Educadoras na Perspectiva da Arquitetura e Urbanismo. In Moraes, M. M. S. (Org.). Trajetórias Formativas em Educação Integral no Estado de Mato Grosso do Sul (pp. 141-153). Campo Grande, MS: Ed. UFMS.
Micheleni, M. S. M. (Org.) (2016). Trajetórias formativas em educação integral no estado de Mato Grosso do Sul. Campo Grande: UFMS Molina, M. C., \& Sá, L. M. (2012). Escola do Campo. In Caldart, R. S. et al. (Orgs.). Dicionário da Educação do Campo (pp. 326333). Rio de Janeiro, São Paulo: Escola Politécnica de saúde, Joaquim Venâncio, Expressão Popular.

Moll, J. (Org.). (2009). Educação Integral: texto referência para o debate nacional. Brasília: MEC/SECAD.

Moraes, M. M. S., \& Aniceto, K. R. P. (2016). Educação Integral: da Paidéia aos dias de hoje. In Moraes, M. M. S. (Org.). Trajetórias Formativas em Educação Integral no Estado de Mato Grosso do Sul (pp. 23-43). Campo Grande, MS: Ed. UFMS.

Nascimento, C. G. (2009). Educação do Campo e Políticas Públicas para além do capital: Hegemonia em disputa. (Tese de Doutorado). Universidade de Brasília, Brasília.

Paro, V. H. et al. (1988a). Escola de tempo integral: desafio para o ensino público. São Paulo: Cortez; Autores Associados.

Paro, V. H. et al. (1988b). Viabilidade da Escola Pública em Tempo Integral. Educação e Sociedade, 10(29), 86-99.

Paro, V. H. (2013). Vantagens e desvantagens da Escola de tempo integral, TV Brasil, vídeo youtube. Recuperado de: https://www.youtube.com/watch?v=SOnAmD $\underline{\text { hbmg8 }}$

Piatti, C. B. (2016). Educação Integral: tempos e espaços educativos - que tempos são esses? In Moraes, M. M. S. (Org.). Trajetórias Formativas em Educação Integral no Estado de Mato Grosso do Sul. (pp. 79-93). Campo Grande, MS: Ed. UFMS.

Rosseto, E. R. A. (2005). Os processos de formação dos educadores e educadoras das escolas do campo: Uma análise da experiência na escola EMEF Prof. Hermínio Pagôtto (Trabalho de Conclusão de Curso). Universidade de Brasília, Brasília. 
Recebido em: 04/05/2017

Aprovado em: 21/05/2017

Publicado em: 24/11/2017

\section{Como citar este artigo / How to cite this} article / Como citar este artículo:

APA:

Silva, R. M., \& Sales, A. (2017). Escola em tempo integral no campo: conflitos de ideias. Rev. Bras. Educ. Camp., 2(2), 773-792. DOI: http://dx.doi.org/10.20873/uft.2525-

$\underline{4863.2017 \mathrm{v} 2 \mathrm{n} 2 \mathrm{p} 773}$

\section{ABNT:}

SILVA, R. M.; SALES, A. Escola em tempo integral no campo: conflitos de ideias. Rev. Bras. Educ. Camp., Tocantinópolis, v. 2, n. 2, p. 773-792, 2017.2 DOI: http://dx.doi.org/10.20873/uft.2525$\underline{4863.2017 \mathrm{v} 2 \mathrm{n} 2 \mathrm{p} 773}$

\section{ORCID}

Rosa Maria da Silva

(iD) http://orcid.org/0000-0002-0452-5678

Antonio Sales

D http://orcid.org/0000-0001-5515-6625 